\section{Helicobacter pylori best treatment approach: should a national consensus be the best consensus?}

\section{Christos Liatsos ${ }^{a}$, Sotirios D. Georgopoulos ${ }^{b}$}

A significant number of national and international consensuses have been published in the literature during recent years concerning the treatment of Helicobacter pylori (H. pylori). These guidelines are aimed toward achieving an extremely high cure rate $(\geq 90 \%)$, which seems to be unachievable in real-world settings, especially in areas with high clarithromycin resistance, such as southern Europe [1]. Times change quickly and, as with other infectious diseases, we are moving inevitably from a trial-and-error therapeutic approach to a susceptibility-based one. Empirical firstline treatments should be based on what works best in each geographical and/or national area and must take into account the prevalence of antimicrobial resistance in each region.

We have reviewed the basic conclusive suggestions from the existing guidelines and consensuses worldwide concerning the best anti-H. pylori treatment approach in relation to antibiotic resistance (Table 1) [2-13]. According to this global plethora of recommendations, it is worth remembering that the determinants of a successful $H$. pylori eradication could be divided into host-related (e.g. previous antibiotic exposure, patient's adherence to a multi-drug regimen and/or genetic factors) and $H$. pylori-related factors, with antibiotic sensitivity appearing to be the most important and consistent predictor of success, both in clinical trials and in population-based studies of $H$. pylori eradication $[14,15]$.

Table 1 Basic conclusive suggestions and data concerning the best approach to $H$. pylori treatment from the worldwide existing guidelines and consensuses in relation to antibiotic resistance

\begin{tabular}{|c|c|}
\hline $\begin{array}{l}\text { H. pylori } \mathrm{Tx} \\
\text { Consensuses/Guidelines }\end{array}$ & $\begin{array}{l}\text { Basic conclusive suggestions concerning the best } \mathrm{Tx} \text { approach } \\
\text { in relation to antibiotic resistance }\end{array}$ \\
\hline \multicolumn{2}{|l|}{ WEST } \\
\hline American (North) [2] & $\begin{array}{l}\text { Clinicians are encouraged to make decisions based upon local antibiotic resistance data, whenever available } \\
\text { Clinicians are encouraged to ask patients about previous exposure to macrolides as a surrogate for clarithromycin } \\
\text { resistance }\end{array}$ \\
\hline American (Latin) [3] & $\begin{array}{l}\text { Determination of antibiotic susceptibility of } H \text {. pylori before Tx may improve the effectiveness of Tx and should } \\
\text { be used when available, particularly in populations with high prevalence of resistance } \\
\text { Antibiotic resistance of } H \text {. pylori should be monitored by systematic surveillance in all countries throughout the } \\
\text { region } \\
\text { A systematic effort to monitor the regional frequency and evolution of } H \text {. pylori antibiotic resistance would be } \\
\text { very helpful for designing the best options for empiric Tx }\end{array}$ \\
\hline Canadian [4] & $\begin{array}{l}\text { The systematic evaluation of evidence relied on studies in which the populations had variable percentages of } \\
\text { antibiotic resistance } \\
\text { This would affect the success rates of the different regimens and conclusions may not be generalizable to specific } \\
\text { practice populations }\end{array}$ \\
\hline $\begin{array}{l}\text { European } \\
\text { (Maastricht V) [5] }\end{array}$ & $\begin{array}{l}\text { For any regimen, the eradication rate can be predicted if the cure rates are known for susceptible and resistant } \\
\text { strains and the prevalence of resistance in the population } \\
\text { Population results are not transferable to other geographical areas with different patterns of resistance }\end{array}$ \\
\hline Irish [6] & $\begin{array}{l}\text { As antibiotic resistance is a constantly evolving process, an ongoing effort to monitor antibiotic resistance } \\
\text { rates should be made at a National level with centralized data collection established to accurately monitor the } \\
\text { prevalence of resistance }\end{array}$ \\
\hline Italian [7] & $\begin{array}{l}\text { When choosing an empirical first-line regimen among those recommended, Italian physicians should take into } \\
\text { account what works best in their clinical practice and in their region, as well as the patient's preference }\end{array}$ \\
\hline UK (NICE) [8] & $\begin{array}{l}\text { Standard, 7-day Tx course with PPI-AMO-CLA or MET as the first-line Tx } \\
\text { Take into account previous exposure to CLA or metronidazole } \\
\text { Discuss Tx adherence with individual person and emphasize its importance }\end{array}$ \\
\hline Spanish [9] & $\begin{array}{l}\text { The choice of first-line } H \text {. pylori Tx will depend primarily on the rate of resistance of this bacterium to the } \\
\text { antibiotics prescribed (mean adult CLA resistance rate: 18\%) }\end{array}$ \\
\hline \multicolumn{2}{|l|}{ EAST } \\
\hline Australian [10] & $\begin{array}{l}\text { Pre-Tx Australian CLA resistance: } 5-7 \% \text {, likely to rise } \\
\text { Standard, } 7 \text {-day course, PPI-based triple Tx as the first-line Tx }\end{array}$ \\
\hline
\end{tabular}


Table 1 (Continued)

\begin{tabular}{ll}
\hline $\begin{array}{l}\text { H. pylori Tx } \\
\text { Consensuses/Guidelines }\end{array}$ & $\begin{array}{l}\text { Basic conclusive suggestions concerning the best Tx approach } \\
\text { in relation to antibiotic resistance }\end{array}$ \\
\hline Chinese [11] & $\begin{array}{l}\text { Drug resistance markedly influences the eradication rate } \\
\text { The characteristics of drug resistance should be fully considered in the process of drug selection }\end{array}$ \\
& $\begin{array}{l}\text { The revised Japanese guidelines for } H . p y l o r i \text { are based on scientific evidence } \\
\text { They are considering altering the first-line Tx in the next version of guidelines after more data have accumulated } \\
\text { in Japan }\end{array}$ \\
& $\begin{array}{l}\text { It is believed that the current primary CLA resistance rate remains around } 30 \% \\
\text { S12] }\end{array}$ \\
Standard, $10-14$ days, PPI-based triple regimen should be the first-line Tx. Alternative choices: 10 -day sequential \\
or 10-day concomitant Tx \\
A survey of 5 teaching hospitals revealed that the CLA resistance rate in Thailand varies from 5-29.20\% \\
Avoid using resistant antibiotics
\end{tabular}

H. pylori, Helicobacter pylori; Tx, treatment; PPI, proton-pump inhibitor; AMO, amoxicillin; CLA, clarithromycin; MET, metronidazole

Thus, it is of major importance for a country's clinical practitioners to know the local pattern of resistance. It seems apparent that an international consensus should play a major role in a specialist's decision making, but it also appears quite reasonable and inevitable that a national consensus, based on nationwide surveys of first-line, second-line and rescue therapies, as well as the local prevalence of antibiotic resistance, should play the major role in each clinician's judgment. In a recently published review, De Francesco et al provided a critical reappraisal of updated worldwide guidelines [16]. The authors fairly concluded that, although several of these guidelines highlighted that the results being achieved by an eradication therapy are population-specific and not directly transferable to another one, it emerged that some therapeutic regimens are recommended or discouraged with no mention of the need to consult existing national data. However, if solid susceptibility data are available for a specific population, then one could recommend or reject various therapeutic regimens for this population, because antimicrobial resistance seems to represent the key factor adversely affecting the outcome of eradication treatment. Nevertheless, each national study group and consensus panel should avoid taking isolated data from one study in a specific region of the country and arbitrarily generalizing them to the entire country's population. On the other hand, this extrapolation seems to be generally accepted for one country if its susceptibility pattern has been thoroughly defined.

It seems that the best treatment approach to $H$. pylori is running at full speed toward treatments based on a national consensus that should exist for each country. Undoubtedly, guidelines of a neighboring country or a continental consensus could be used in a tutorial manner, particularly when local information is lacking.

\section{References}

1. Liatsos C, Leontiadis GI. The "report card" to grade H. pylori treatment regimens: is it achievable in real-world in areas with high clarithromycin resistance? J Gastrointestin Liver Dis 2017;26:203-204.

2. Chey WD, Leontiadis GI, Howden CW, Moss SF. ACG Clinical Guideline: Treatment of Helicobacter pylori infection. Am J Gastroenterol 2017;112:212-239.

3. Rollan A, Arab JP, Camargo MC, et al. Management of Helicobacter pylori infection in Latin America: a Delphi technique-based consensus. World J Gastroenterol 2014;20:10969-10983.

4. Fallone CA, Chiba N, van Zanten SV, et al. The Toronto consensus for the treatment of Helicobacter pylori infection in adults. Gastroenterology 2016;151:51-69.

5. Malfertheiner P, Megraud F, O'Morain CA, et al; European Helicobacter and Microbiota Study Group and Consensus panel. Management of Helicobacter pylori infection-the Maastricht V/ Florence Consensus Report. Gut 2017;66:6-30.

6. Smith S, Boyle B, Brennan D, et al. The Irish Helicobacter pylori Working Group consensus for the diagnosis and treatment of H. pylori infection in adult patients in Ireland. Eur J Gastroenterol Hepatol 2017;29:552-559.

7. Zagari RM, Romano M, Ojetti V, et al. Guidelines for the management of Helicobacter pylori infection in Italy: The III Working Group Consensus Report 2015. Dig Liver Dis 2015;47:903-912.

8. National Institute for Health and Care Excellence (NICE) guidelines: Gastro-Oesophageal Reflux Disease and dyspepsia: investigation and management (CG184). NICE 2014:1-41. www. nice.org.uk/guidance/cg184/resources/gastrooesophageal-refluxdisease-and-dyspepsia-in-adults-investigation-and-managementpdf-35109812699845

9. Gisbert JP, Molina-Infante J, Amador J, et al. IV Spanish Consensus Conference on Helicobacter pylori infection treatment. Gastroenterol Hepatol 2016;39:697-721.

10. Antibiotic Expert Group. Eradication of Helicobacter pylori and ulcer healing In: eTG Complete [Internet] Melbourne. Therapeutic Guidelines Ltd. 2013. Available at www.tg.org.au [Accessed 15 March 2013].

11. Liu WZ, Xie Y, Cheng H, et al; Chinese Society of Gastroenterology, Chinese Study Group on Helicobacter pylori. Fourth Chinese National Consensus Report on the management of Helicobacter pylori infection. J Dig Dis 2013;14:211-221.

12. Asaka M, Kato M, Takahashi S, et al; Japanese Society for Helicobacter Research. Guidelines for the management of Helicobacter pylori infection in Japan: 2009 revised edition. Helicobacter 2010;15:1-20. 
13. Mahachai V, Vilaichone RK, Pittayanon R, et al. Thailand Consensus on Helicobacter pylori Treatment 2015. Asian Pac J Cancer Prev 2016;17:2351-2360.

14. Papastergiou V, Georgopoulos SD, Karatapanis S. Treatment of Helicobacter pylori infection: past, present and future. World $J$ Gastrointest Pathophysiol 2014;5:392-399.

15. Papastergiou V, Georgopoulos SD, Karatapanis S. Treatment of Helicobacter pylori infection: meeting the challenge of antimicrobial resistance. World J Gastroenterol 2014;20:9898-9911.

16. De Francesco V, Bellesia A, Ridola L, Manta R, Zullo A. First-line therapies for Helicobacter pylori eradication: a critical reappraisal of updated guidelines. Ann Gastroenterol 2017;30:373-379.
${ }^{\mathrm{a}}$ Gastroenterology Department, 401 Army General Hospital of Athens (Christos Liatsos); ${ }^{\mathrm{b}}$ Gastroenterology Department, Athens Medical P. Faliron General Hospital (Sotirios D. Georgopoulos), Athens, Greece Conflict of Interest: None

Correspondence to: Christos Liatsos, $\mathrm{MD}, \mathrm{PhD}$, Consultant Gastroenterologist, Gastroenterology Department, 401 Army General Hospital of Athens, Athens, Greece, Fellow of European Board of

Gastroenterology \& Hepatology, PO Box: 833, 19009, Pikermi - Rafina, Greece, e-mail: cliatsos@yahoo.com

Received 5 June 2017; accepted 18 July 2017;

published online 2 August 2017

DOI: https://doi.org/10.20524/aog.2017.0183 